\title{
Effects of flooding and salinity on photosynthesis of Sagittaria lancifolia
}

\author{
S. R. Pezeshki, R. D. DeLaune, W. H. Patrick, Jr. \\ Laboratory for Wetland Soils \& Sediments, Center for Wetland Resources, Louisiana State University, Baton Rouge, Louisiana \\ 70803-7511, USA
}

\begin{abstract}
Sagittaria lancifolia L. plants were subjected to flooding, salinity, and combined treatments. Effects of each treatment and their interaction on stomatal conductance and net photosynthesis were evaluated after $4 \mathrm{wk}$ of acclimation to the imposed conditions. Effect of flooding on leaf conductance was not significant while the salinity effect was significant. Both flooding and salinity reduced net photosynthesis significantly. However, their interaction was not significant. The stomatal limitation of photosynthesis was relatively small ranging from 12 to $18 \%$. Results indicated that for plants subjected to salinity or to combined salinity and flooding, photosynthetic capacity was reduced through stomatal limitations as well as non-stomatal (metabolic) factors.
\end{abstract}

\section{INTRODUCTION}

The Gulf coast of Louisiana, USA, is currently experiencing rapid increases in water level and salinity primarily due to subsidence in the Mississippi River Deltaic Plain (Salinas et al. 1986). If the increases in sea level continues to occur as rapidly as predicted (Hoffman et al. 1983), the combined effects of increased salinity and water level will place stress on wetland vegetation in the coastal marshes of Louisiana as well as of other coastal regions. The impact is likely to be particularly severe in freshwater marshes where plants are more susceptible to saltwater intrusion. To date there is little information on the extent to which increases in salinity affect the physiology of vegetation found in coastal freshwater marshes. Although limited physiological data from intermediate and brackishwater marsh species suggest an adverse response to increased salinity, these effects have not been documented for the major coastal wetland plant species of the U. S. Gulf coast region.

It is not known what adverse effects these 2 stresses may have on physiological processes such as photosynthesis, or on the consequent survival and productivity of coastal vegetation. The combination of raised salinity and anoxia may result in the elimination of plants such as Sagittaria lancifolia L., a dominant species occupying freshwater marshes in the southeastern United States. S. lancifolia ('bulltongue') is a perennial herb growing in dense stands in fresh marshes. Its range also extends into intermediate marsh types.

Survival and growth of a given species when exposed to sub-lethal stress conditions is dependent upon its ability to maintain a functional photochemical and biochemical system enabling maintenance of positive net carbon fixation. The present study was designed to evaluate the photosynthetic response of Sagittaria lancifolia plants to flooding and salinity. Specific objectives were to evaluate: (1) the extent to which stomatal and non-stomatal components affect photosynthetic rates, under reduced soil redox potential and increased salinity conditions; and (2) the response of photosynthesis to flooding, salinity, and their interaction.

\section{MATERIALS AND METHODS}

Sagittaria lancifolia plants were collected from the Barataria Basin freshwater marsh, Louisiana, USA. Plants were transferred into pots $30 \mathrm{~cm}$ deep and $25 \mathrm{~cm}$ diameter and kept in a greenhouse. The study pots were watered to excess daily and were fertilized once a month with a commercial plant food (20-20-20 N-P-K, respective percentages). In April 198616 plants were selected for uniformity and randomly assigned to 4 replicate experiments each composed of 4 treatments ( 1 plant treatment $\left.{ }^{-1}\right)$. Treatments consisted of: a well- 
watered control with no flooding or salt stress (Treatment I); well-watered, but not flooded, with soil salinity maintained at $50 \mathrm{~mol} \mathrm{~m}^{-3}(=2.9 \%$ ) (Treatment II); flooded with saltwater containing $50 \mathrm{~mol} \mathrm{~m}^{-3}$ salt (Treatment III); and flooded with tap water containing no salt (Treatment IV).

Experimental procedures. Salt solutions were prepared using Instant Ocean Synthetic Sea Salt (Aquarium Systems Inc., Mentor, Ohio, USA). Salt treatment began by flooding and/or adding salt to the pots to raise the salinity to the pre-determined levels. The salt was added gradually to the soil medium over the first 2 wk of the experiment (Days 1 to 14). For all flooded treatments, the water level in each pot was maintained approximately $5 \mathrm{~cm}$ above soil surface during the study. Salinity levels were monitored in all pots throughout the experiment using a YSI Model 33 SCT meter (Yellow Springs Instrument Co., Yellow Springs, Ohio, USA). Control plants were watered to excess as required to maintain well-watered but not flooded conditions.

Diumal measurements of photosynthetic photon flux density (PPFD), air temperature and relative humidity, stomatal conductance $\left(g_{w}\right)$, net photosynthesis $\left(P_{n}\right)$, and leaf temperature were made on one sample leaf per plant every $3 \mathrm{~h}$ from $0700 \mathrm{~h}$ until $1900 \mathrm{~h}$ on each sample day. There were 7 sample days during the experiment, the first on Day 30 and the last on Day 45.

Stomatal conductance was measured using a steadystate porometer (LI-1600, Licor, Inc., Lincoln, Nebraska, USA). After recording $g_{w}$, the same leaf was used for $P_{n}$ measurements. A portable gas exchange system (Model A120, ADC [Analytical Development Company, North Andover, Massachusetts, USA], Field Analytical System) was used for quick measurements of net photosynthesis. The system was composed of 3 major components: (1) ADC Parkinson Leaf Chamber; (2) an infrared $\mathrm{CO}_{2}$ analyzer, ADC Model LCA-2; and (3) an air supply unit controlling the humidity and flow of the incoming air. The leaf was enclosed in the chamber and differential $\mathrm{CO}_{2}$ level was recorded. Mature, well-developed leaves were used for all measurements

On Day 46 the plants were transferred to a growth chamber. The environmental conditions in the growth chamber were maintained at daylength $16 \mathrm{~h}\left(25^{\circ} \mathrm{C}\right.$, $70 \%$ relative humidity $)$ and nights of $8 \mathrm{~h}\left(20^{\circ} \mathrm{C}, 85 \%\right.$ relative humidity). The PPFD level was around 1000 $\mu m \mathrm{l} \mathrm{m}^{-2} \mathrm{~s}^{-1}$ at the top of the plant. PPFD was reduced to $300 \mu \mathrm{mol} \mathrm{m} \mathrm{m}^{-2} \mathrm{~s}^{-1}$ during the first and last hour of each photoperiod. Plants were kept in the growth chamber for $48 \mathrm{~h}$ before beginning gas exchange measurements.

Measurements of photosynthetic rates for intact attached leaves were determined in an open gas exchange system located inside a growth chamber.
This system consisted of 3 water-jacketed cuvettes supplied with temperature- and humidity-conditioned air, where the temperature of each cuvette was maintained at the desired level by changing water temperature and air was stirred by an internal fan. Since the air in each cuvette was preconditioned to the same temperature and humidity level as air within the growth chamber, temperature of the cuvette remained within 2 to $3^{\circ} \mathrm{C}$ of the preconditioned air temperature, preventing the occurrence of condensation within the cuvettes. An infrared gas analyzer, ADC Model LCA-2, was again used for differential $\mathrm{CO}_{2}$ measurements. Pre- and post-cuvette humidity measurements were made with humidity sensors. Changes in $P_{n}$ rates as a function of the intercellular $\mathrm{CO}_{2}$ concentration, $\mathrm{C}_{\mathrm{i}}$ were measured by changing the chamber $\mathrm{CO}_{2}$ concentrations according to the sequence $330,400,250,200$, 150,100 , and $50 \mu \mathrm{l} \mathrm{l}^{-1}$ allowing at least $30 \mathrm{~min}$ at each concentration for steady-state readings. The method outlined by Farquhar \& Sharkey (1982) was used to calculate the relative stomatal limitation $\left(\mathrm{L}_{\mathrm{s}}\right)$ to $\mathrm{CO}_{2}$ uptake. Accordingly, $\mathrm{L}_{\mathrm{s}}$ was defined as the percentage of reduction in $P_{n}$ rates due to limitations caused by stomatal conductance relative to the $P_{n}$ rates which would be expected under non-limiting stomatal conductance.

Both $g_{w}$ und $P_{n}$ were calculated per unit leaf area (single surface) determined with a surface area meter (Model S1701, SKYE Instruments, Inc., Buckingham, Pennsylvania USA). Net photosynthetic rates were calculated from the flow rate of air and from the $\mathrm{CO}_{2}$ partial pressure differences between incoming and outgoing air through the chamber as outlined by Caemmerer \& Farquhar (1981). Leaf internal $\mathrm{CO}_{2}$ concentration was calculated from $P_{n}$ and $g_{w}$ values using the equations of Caemmerer \& Farquhar (1981).

The General Linear Models (GLM) procedures of SAS (Statistical Analysis System, SAS Institute, Inc., Cary, North Carolina, USA) was used to detect significant differences among the variable means for different treatments.

\section{RESULTS}

\section{Diffusional limitations of net photosynthesis}

To evaluate the effect of saltwater treatment on the photosynthetic process of Sagittaria lancifolia leaves, the response of $P_{n}$ to a range of $C_{i}$ was measured for plants under different treatments (Fig. 1). A shift in the initial slope of the response to $C_{i}$ occurred as a result of flooding and salinity. Also, both flooding and salinity treatments caused changes in the $\mathrm{CO}_{2}$-saturated portion of the curve. However, the $\mathrm{CO}_{2}$ compensation 


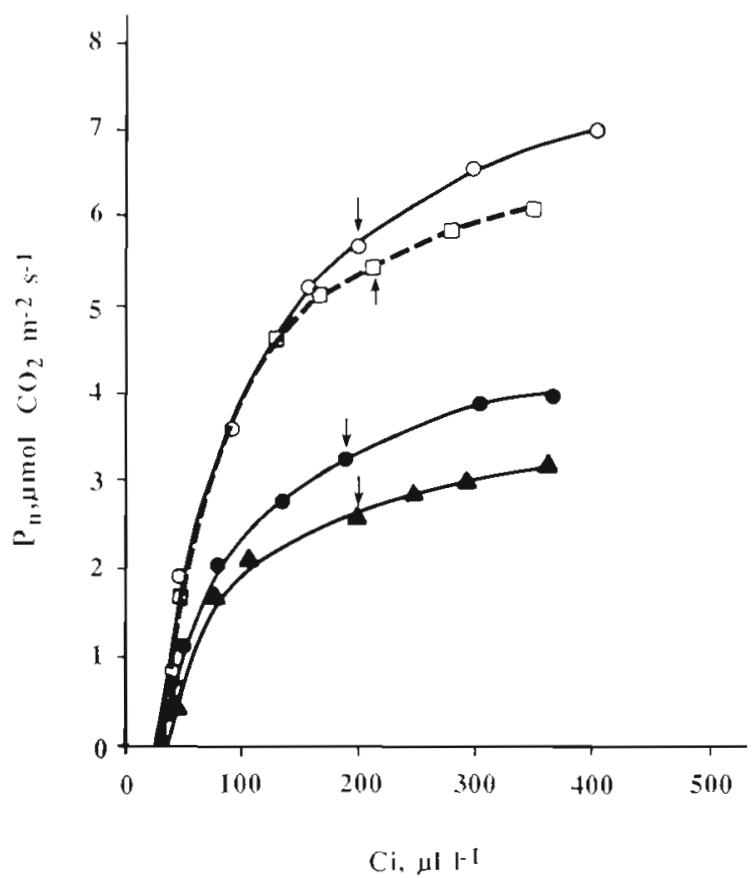

Fig. 1. Sagittaria lancifolia. Response of net photosynthesis $\left(\mathrm{P}_{\mathrm{n}}\right)$ to changes in intercellular $\mathrm{CO}_{2}$ concentrations $\left(\mathrm{C}_{\mathrm{i}}\right)$ for plants under (O) Treatment I, control; (•) Treatment II, saltstressed; (1) Treatment III, flooded with saltwater; (ㅁ) Treatment IV, flooded. Arrows indicate $P_{n}$ rates obtained at ambient $\mathrm{CO}_{2}$ conditions of $338 \mu \mathrm{l}^{-1}$ Measurements were made at photosynthetic photon flux density $800 \mu \mathrm{mol} \mathrm{m}^{-2} \mathrm{~s}^{-1}$. leaf temperature $25^{\circ} \mathrm{C}$, and leaf-to-air vapor pressure difference $1.5 \mathrm{kPa}$

point (the internal $\mathrm{CO}_{2}$ concentration at which $\mathrm{P}_{\mathrm{n}}=0$, i.e. gross photosynthesis $=$ respiration) did not change as a result of treatments. Analysis of Fig. 1 shows that the relative stomatal limitation $\left(\mathrm{L}_{\mathrm{s}}\right)$ was small. In Treatment III and Treatment IV plants, $\mathrm{L}_{\mathrm{s}}$ was 18 and $12 \%$, respectively. $L_{s}$ was around $17 \%$ for plants in Treatment II. As pointed out by Sharkey (1985), the method of calculating stomatal limitations does not account for the effect of transpiration on gas exchange. Therefore, the calculated limitations may slightly overestimate the actual reduction in $P_{n}$ caused by stomatal closure. The results of this experiment suggest that for different treatments, $P_{n}$ capacity was reduced through diffusional limitations caused by stomatal closure as well as non-stomatal inhibition of net photosynthesis

\section{Diurnal patterns of stomatal conductance and net photosynthesis}

In a typical diurnal course, $g_{w}$ increased as light levels increased in Treatment I, II, and IV. A slight stomatal closure was noted around $1300 \mathrm{~h}$ followed by increases in $\mathrm{g}_{\mathrm{w}}$ around $1600 \mathrm{~h}$ (data not shown). The $\mathrm{g}_{\mathrm{w}}$ rates declined again around $1900 \mathrm{~h}$ in response to the decreasing PPFD levels. In Treatment III (saltwater flooding) the response patterns were different. Values of $g_{w}$ were considerably lower than other treatments and the normal stomatal response to PPFD and leaf-toair vapor pressure difference (VPD) was not apparent.

Diurnal patterns of photosynthesis for control plants (Treatment I) showed an increase in $\mathrm{P}_{\mathrm{n}}$ with maximum rates measured around $1600 \mathrm{~h}$ (data not shown). In Treatments II and IV maximum $P_{\Omega}$ rates were observed around $1300 \mathrm{~h}$. In Treatment III, the normal $\mathrm{P}_{\mathrm{n}}$ response patterns were modified. The stomata were less responsive to changes in PPFD and VPD as compared to the control plants. Overall $g_{w}$ and $P_{n}$ rates were substantially lower for plants under salt stress (Treatment II) and those under combined stresses (Treatment III), compared to other treatments. It is important to note that the conditions of conducting the experiment may have partially affected plant responses particularly by enhancing transpiration rates despite the fact that the greenhouse was ventilated adequately and maximum VPD did not exceed $2.8 \mathrm{kPa}$.

\section{Effect of flooding, salinity and interactions}

Table 1 presents average values for hourly diurnal measurements recorded for different treatments on the 7 sampling days between Days 30 and 45. As shown, average daily $g_{w}$ and $P_{n}$ for salt-treated plants (Treatment II) decreased 34 and $37 \%$, respectively, compared to control plants. The decreases were $67 \%$ in $\mathrm{g}_{\mathrm{w}}$ and $45 \%$ in $\mathrm{P}_{\mathrm{n}}$ for plants under saltwater (Treatment III), and $19 \%$ in $\mathrm{g}_{\mathrm{w}}$ and $26 \%$ in $\mathrm{P}_{\mathrm{n}}$ for flooded plants (Treatment IV), compared to control plants. The statistical significance of each treatment on $g_{w}$ and $P_{n}$ is presented in Table 2. Flooding alone did not reduce $g_{w}$ significantly but did affect $P_{n}$ significantly. Salt alone caused significant reduction in both $g_{w}$ and $P_{n}$. However, the interaction between flood and salt was not significant.

\section{DISCUSSION}

The photosynthetic capacity of Sagittaria lancifolia leaves declined with addition of salt to flood water as is evident from changes in the $\mathrm{P}_{n}$ vs $\mathrm{C}_{1}$ relation (Fig. 1). The initial slope in the linear portion of the curve was reduced and there was a decline in the $\mathrm{CO}_{2}$-saturated portion of the curve. Similar changes in the response of $\mathrm{P}_{\mathrm{n}}$ rates to $\mathrm{C}_{\mathrm{i}}$ have been reported in other studies on changing salinity conditions. Ball \& Farquhar (1984a) reported that long-term exposure of 2 mangroves, Aegiceras corniculatum (L.) Blanco and Avicennia marina (Forstk.) Vierh. var. australasica (walp), to high 
Table 1. Sagittaria lancifolia. Mean stomatal conductance $\left(g_{w}\right)$ and net photosynthesis $\left(P_{n}\right)$ for plants, recorded between 0700 and $1900 \mathrm{~h}$ for 7 sample days in the greenhouse. Treatments are: I, control, II, sait only; III, flood and salt; and IV, flood only. Values are means $\pm \mathrm{SE}$

\begin{tabular}{lcccc|}
\hline Variable & I & Treatment & III & IV \\
\hline $\mathrm{g}_{\mathrm{w}}\left(\mathrm{mmol} \mathrm{H}_{2} \mathrm{O} \mathrm{m}^{-2} \mathrm{~s}^{-1}\right)$ & $366 \pm 27$ & $243 \pm 24$ & $121 \pm 9$ & $296 \pm 11$ \\
$\mathrm{P}_{\mathrm{n}}\left(\mu \mathrm{mol} \mathrm{CO} \mathrm{m}^{-2} \mathrm{~s}^{-1}\right)$ & $3.8 \pm 0.23$ & $2.4 \pm 0.19$ & $2.1 \pm 0.16$ & $2.8 \pm 0.17$ \\
\hline
\end{tabular}

Table 2. Sagittaria lancifolia. Statistical significance of different treatments and their interaction on stomatal conductance $\left(\mathrm{g}_{\mathrm{w}}\right)$ and net photosynthesis $\left(\mathrm{P}_{\mathrm{n}}\right)$

\begin{tabular}{|lccc|}
\hline Variable & Flood & $\begin{array}{c}\text { Treatment } \\
\text { Salt }\end{array}$ & Flood $\times$ Salt \\
\hline $\mathrm{g}_{w}$ & $N S$ & $\cdots$ & $N S$ \\
$\mathrm{P}_{\mathrm{n}}$ & $\cdots$ & $\cdots$ & $\mathrm{NS}$ \\
$\cdots$ Significant $(p<0.05) ;$ NS: not significant $(p>0.05)$ \\
\hline
\end{tabular}

salinity caused reduction in the initial slope and the $\mathrm{CO}_{2}$-saturated portion of the $P_{n}$ response curve, whereas short-term exposure appeared to affect $P_{n}$ rates at high $\mathrm{CO}_{2}$ concentrations (Ball \& Farquhar 1984b). Caemmerer \& Farquhar (1984) noted a similar response for Phaseolus vulgaris L. plants under severe water stress conditions. Seemann \& Critchley (1985), using a similar approach, found a decline both in the initial slope and $\mathrm{CO}_{2}$-saturated portion of the $\mathrm{P}_{\mathrm{n}}$ vs $\mathrm{C}_{\mathrm{i}}$ curve in salt-stressed $P$. vulgaris plants.

In the present study, stomatal limitation was low, ranging from 12 to $18 \%$ depending on the treatment. This is attributed to some stomatal reopening because the measurement of the $P_{n} v s C_{1}$ relation was conducted late in the experiment when some stomatal adjustment to the imposed conditions were evident. It appears that the reduction in $P_{n}$ rate under different treatments was caused by both diffusional limitations as well as nonstomatal (metabolic) inhibition of photosynthesis. This finding agrees with previous reports for several other species (Walker et al. 1981, 1982). Under a constant salinity level, a continuing decrease in $\mathrm{P}_{\mathrm{n}}$ with time has been reported in some species (Walker et al. 1982, Yeo et al. 1985)

The decline in $P_{n}$ capacity may be related to increases in leaf tissue ion concentrations, especially $\mathrm{Na}^{+}$or $\mathrm{K}^{+}$and in the ratio of $\mathrm{Na}^{+} / \mathrm{K}^{+}$. Such ionic imbalances have been demonstrated by Ball \& Farquhar (1984b). Salt concentrations may increase in both old and young leaves of glycophytes (Greenway \& Munns 1980, Walker et al. 1982, Yeo et al. 1985). The ion build-up in these plants may continue until leaf death (Yeo et al. 1985). High leaf tissue ionic concentrations resulting from soil salinity could cause disturbances in metabolic processes resulting in the decline of photosynthesis. Seemann \& Critchley (1985) found a high concentration of chloride in the chloroplast cytoplasm of Phaseolus vulgaris plants subjected to salinity. Direct effects of excess salt on various plant biochemical and structural functions which can cause reductions in $P_{n}$ capacity have been documented by Chimiklis \& Karlander (1973), Helal \& Mengel (1981), and Longstreth et al. (1984).

In the present study, the impact of different treatments on net photosynthesis was greater in plants exposed to saltwater than those flooded with tap water. However, the interaction between flooding and salinity was not significant. We attribute this finding to the low level of salt in the study as well as the relatively short period of our experiment. It is important to note that the salinity level of $50 \mathrm{~mol} \mathrm{~m} \mathrm{~m}^{-3}$ imposed in this study was not lethal (at least for the duration of the experiment), and that higher salinity and/or longer exposure may change the response considerably.

Louisiana's Mississippi River deltaic plain is currently experiencing rapid increases in submergence and saltwater intrusion as a result of several natural and man-made causes including subsidence (Salinas et al. 1986), numerous canals running perpendicular to the coast, and brine discharge into freshwater habitats associated with oil extraction operations. The present findings suggest that the increase in salinity in otherwise normally freshwater habitats colzld be having a major adverse effect on physiological processes controlling gas exchange and photosynthesis of Sagittaria lancifolia in the extensive freshwater marshes of the U.S. Gulf Coast.

Acknowledgements. Funding for this project was provided by the National Science Foundation, Grant \#BSR-841006.

\section{LITERATURE CITED}

Ball, M. C., Farquhar, G. D. (1984a). Photosynthetic and stomatal responses of two mangrove species to long-term salinity and humidity conditions. Plant Physiol. 74: 1-6 
Ball, M. C., Farquhar, G. D. (1984b). Photosynthetic and stomatal responses of the grey mangrove to transient salinity conditions. Plant Physiol. 74: 7-11

Caemmerer, S. von, Farquhar, G. D. (1981). Some relationships between the biochemistry of photosynthesis and the gas exchange of leaves. Planta 153: 376-387

Caemmerer, S. von, Farquhar, G. D. (1984). Effects of partial defoliation, changes of irradiance during growth at enhanced $\mathrm{P}\left(\mathrm{CO}_{2}\right)$ on the photosynthetic capacity of leaves of Phaseolus vulgaris L. Planta 160: 320-329

Chimiklis, P. E., Karlander E. P., (1973). Light and calcium interaction in Chlorella inhibited by sodium chloride. Plant Physiol. 51: 48-56

Farquhar, G. D., Sharkey, T. D. (1982). Stomatal conductance and photosynthesis. A. Rev. Pl. Physiol. 33: 317-345

Greenway, H., Munns, A. (1980). Mechanism of salt tolerance in non-halophytes. Ann. Rev. Plant Physiol. 31: 149-190

Helal, H. H., Mengel, K. (1981). Interaction between light intensity and $\mathrm{NaCl}$ salinity and their effects on growth, $\mathrm{CO}_{2}$ assimilation, and photosynthate conversion in young broad beans. Plant Physiol. 67: 999-1002

Hoffman, J. S., Keyes, D., Tutus, J. G. (1983). Projecting future sea level rise. Methodology, estimates to the year 2100, and research needs. U. S. Environmental Protection Agency Report \#EPA. 230-09-007, Washington, D.C.
Longstreth, D. J., Bolanos, J. A., Smith, J. E. (1984). Salinity effect on photosynthesis and growth in Alternanthera philoxedroides. Plant Physiol. 75: 1044-1047

Salinas, L. J., De Laune R. D., Patrick, W. H. Jr. (1986). Changes occurring along a rapidly submerging coastal area: Louisiana USA. J. coast. Res. 2(3): 269-284

Seemann, J. R., Critchley, C. (1985). Effect of salt stress on the growth, ion content, stomatal behavior and photosynthetic capacity of a salt-sensitive species Phaseolus vulgaris L. Planta 164: 151-162

Sharkey, T D. (1985). Photosynthesis in intact leaves of $C_{3}$ plants: physics, physiology and rate limitations. Bot. Rev. 1 (51): 53-105

Walker, R. R., Torokfalvy, E., Downton, W. J. S. (1982). Photosynthetic responses of citrus varieties, Rangepur lime and Etrog citron to salt treatment. Aust. J. Plant Physiol. 9: $783-790$

Walker, R. R., Torokfalvy, E., Scott, N. S. Kriedemann, P. E. (1981). An analysis of photosynthetic response to salt treatment of Vitis vinifera. Aust. J. Plant Physiol. 8: 359-374

Yeo, A. R., Caporn, S. J. M., Flowers, T. J. (1985). The effect of salinity upon photosynthesis of rice (Oryza sativa L.): gas exchange by individual leaves in relation to their salt content. J. exp. Bot. 36: 1240-1248 